\title{
Epidural levobupivacaine versus levobupivacaine-morphine in postoperative analgesia for paediatric patients
}

\author{
Önal Danyal ${ }^{1}$, Hatipoglu Zehra ${ }^{1 *}$, Ozcengiz Dilek ${ }^{1}$, Gunes Yasemin ${ }^{1}$ and Gündüz Murat ${ }^{1}$
}

\begin{abstract}
Background: We compared the effects of epidural levobupivacaine and levobupivacaine plus morphine administration on postoperative analgesia in children undergoing major abdominal surgery.

Methods: After the approval by our Faculty Ethic Committee and informed consent of parents were taken, 47 children, aged between 1-14 year, undergoing major abdominal surgery were included. Following the anesthesia induction, an epidural catheter (22-24 G) was inserted by using Tuohy needle (19-20 G). Patients were randomly divided iiinto two groups. Epidural block was performed with levobupivacaine $(0.125 \%)$ plus morphine $(30 \mu \mathrm{g} / \mathrm{kg})$ in group I patients, and sole levobupivacaine $(0.25 \%)$ in group II patients. Peroperative sevoflurane concentration, systolic and diastolic blood pressure and heart rate were recorded. Pain and sedation scores were recorded postoperatively. Side effects and the number of patients who required rescue analgesics were noted.

Results: Sevoflurane concentrations were lower in group I patients than in group II patients at 10th and 30th minutes intraoperatively. In the first postoperative day, the number of the patients who required rescue analgesic was 7 in group I and 18 in group II $(p=0.003)$. The duration of postoperative analgesia was longer in group I patients than group II patients $(p=0.002)$. Pain and sedation scores were lower in group I patients than group II patients $(p<0.05)$. No patient experienced hypotension, bradycardia or respiratory depression.

Conclusion: We concluded that, epidural levobupivacaine plus morphine combination reduced intraoperative anesthetic concentration, supplied longer postoperative analgesia and required less rescue postoperative analgesic than sole levobupivacine, but it caused higher sedation.
\end{abstract}

\section{Introduction}

Postoperative pain relief provides early ambulation and reduces postoperative complications. Epidural anesthesia/analgesia is a safe and effective regional anesthetic/ analgesic management in pediatric surgical patients [1-3]. Bupivacaine has been the drug of choice for postoperative epidural analgesia in children. Although bupivacaine has been used extensively for caudal and epidural blocks in children, there have been reports of systemic toxicity. Levobupivacaine is the $\mathrm{S}(+)$ enantiomer of racemic bupivacaine [4,5]. Levobupivacaine could replace bupivacaine in children for postoperative analgesia because of various studies suggests that it is less cardiotoxic than racemic bupivacaine [5-9]. Hovewer, levobupivacaine has similar local anesthetic properties and potency to racemic bupivacaine.

Epidural morphine is used widely in the treatment of pain but may have important side effects such as respiratory depression, sedation, nausea and vomiting [10-12]. Pharmacokinetic parameters were similar to those observed after epidural injection of morphine in adults, except for a shorter terminal half-life [12].

The aim of this investigation was to compare the effect of a postoperative intermitent bolus dose of levobupivacaine or levobupivacaine-morphine combination on intraoperative sevoflurane concentrations, postoperative pain relief and sedation scores after major urological and intestinal surgery.

*correspondence: hatipogluzehra@gmail.com

${ }^{1}$ Cukurova University Faculty of Medicine,

Department of Anesthesiology Adana-Turkey.

\section{Material \& Methods}

This study was done in Cukurova University Faculty of Medicine, at Department of Anesthesiology and Pediatric Surgery. Fourty-seven children with American Society of Anesthesiologists (ASA) physical statatus group I-II, and between the ages of 1 and 14 years, underwent major urological and intestinal surgery were enrolled in this prospective study. Cukurova University Faculty of Medicine Ethics Committee approved the protocol. Written informed consent was obtained. Exclusion criteria were history of hypersensitivity to any drug, history of bleeding diathesis, uncontrolled concomitant medical diseases (juvenile diabetes mellitus), acute exacerbation of bronchial asthma, impaired kidney or liver functions and additional pathology of the spine such as Tethered Cord Syndrome.

Patients arrived unpremedicated in the operating room. Routine monitors were applied for recording heart rate (HR), noninvasive systolic (SBP), diastolic (DBP) blood pressure and peripheral oxygen saturation (Sp02), and urine output (via bladder catheter). All patients received $\% 0.45 \mathrm{NaCl} 5-15 \mathrm{~mL} / \mathrm{kg}$, intravenously. All patients were anesthetised with the same technique. Anesthesia was induced by sevoflurane (end tidal concentration 5-7\%). Muscle paralysis was induced with intravenous vecuronium bromide $(0.1 \mathrm{mg} / \mathrm{kg})$. The concentration of sevoflurane was titrated to the child's anesthetic requirements.

All patients were mechanically ventilated to maintain the endtidal carbon dioxide concentration in the range of $30-35 \mathrm{mmHg}$. Following the induction of anesthesia and tracheal entubation, patients were placed into the left lateral decubitis position and under aseptic 
conditions, an 19-20 G epidural needle was inserted. Repetitive gentle aspiration was performed to demonstrate absence of either vascular cannulation or cerebrospinal fluid. A 22-24 G pediatric epidural catheter was inserted through the needle into the lumbar epidural space (L3-4). Patients were randomly divided into two groups. Epidural block was performed with levobupivacaine $(0.125 \%)$ + morphine $(30 \mu \mathrm{g} / \mathrm{kg})$ in group I patients, and sole levobupivacaine $(0.25 \%)$ in group II patients in each with a volume of $0.7 \mathrm{ml} / \mathrm{kg}$. In these cases, intaroperative sevoflurane concentrations, systolic, diastolic blood pressures and heart rate were recorded at 5, 10, 15, 30, 45, $60,90,120,150$ and 180 minutes. Hypertension and hypotension were defined as a $30 \%$ increase or decrease from baseline blood pressure, respectively. Hypertension was treated by increasing the concentration of sevoflurane. Hypotension was treated firstly by decreasing the concentration of sevoflurane and administering 10 $\mathrm{ml} / \mathrm{kg}$ intravenous boluses of lactated Ringer's solution and secondly by administering vasopressors.

After completion of the surgery, neuromuscular blockade was reversed with atropine $0.02 \mathrm{mg} / \mathrm{kg}$ and neostigmine $0.04 \mathrm{mg} / \mathrm{kg}$. Extubation was carried out when patients with adequate respiratory rate were transferred to the postanesthesia care unit (PACU) for observation.

Pain was assessed using the Children's Hospital of Eastern Ontario Pain Scale (CHEOPS) at 5, 10, 15, 30, 45.th minutes after extubation, and 1, 2, 4, 6, 12, 24 hours. The CHEOPS score was 6 or greater and the clinical assessment was consistent with a diagnosis of pain, rescue medication was administered. Rescue analgesia consisted of an bolus of $0.125 \%$ levobupivacaine $(0.35 \mathrm{ml} / \mathrm{kg})$ as required. The

\begin{tabular}{lc}
\hline Leg movement & Point \\
\hline $\begin{array}{l}\text { No motor block, able to stand unassisted or complete } \\
\text { flexion of ankle knee and thigh flexion in nonwalking } \\
\text { child or at wake-up evaluation }\end{array}$ & 0 \\
$\begin{array}{l}\text { Unable to stand unassisted or partial knee flexion with } \\
\text { complete thigh flexion in nonwalking-child or at wake- } \\
\text { up evaluation }\end{array}$ & 1 \\
$\begin{array}{l}\text { Unable to flex the knee but can flex the ankle } \\
\text { No movement or complete motor blockade in a fully }\end{array}$ & 2 \\
awake child & 3 \\
\hline
\end{tabular}

Table 1. Motor block evaluation

\begin{tabular}{lcc}
\hline & Group I (n=23) & Group II $(\mathbf{n = 2 4})$ \\
\hline Age (year) & $7,08 \pm 3,7$ & $7,10 \pm 3,4$ \\
Gender $(\mathrm{M} / \mathrm{F})$ & $15 / 8$ & $12 / 12$ \\
Weight $(\mathrm{Kg})$ & $21,7 \pm 11,1$ & $22,3 \pm 10,6$ \\
Operation time (minute) & $164 \pm 54,5$ & $158,9 \pm 49,5$ \\
\hline
\end{tabular}

Table 2. Demographic data in groups (Mean \pm SD) duration of analgesia was defined as first rescue analgesia required and this patients were recorded.

Sedation was assessed using sedation 5 points test $(0=$ Awake, $1=$ Mild sedation, $2=$ Sloping to sleep, $3=$ Sleeping, but able to wake, $4=$ Deep sleeping, unable to wake). These observations were made by an experienced anaesthesiologist blinded to the treatment groups. Motor block was assessed using 4 point test (0-1-2-3) (Table 1). All children were evaluated for side effects such as nausea, vomiting and pruritus or any other complication while in hospital and up to 3-5 days after the start of the epidural analgesia.

Twenty four patients per group provided an $80 \%$ power for detecting a $30 \%$ difference for postoperative pain scores between the groups, at an a level of 0.05 . Quantitative data are presented as mean, median, SD or range. The independent $t$ test was used for analysis of differences in age, weight, hemodynamic variables, operation time and analgesic time. ASA physical status, gender, residual motor blockade and number of patients requiring analgesics after operation were analyzed with chi-squared or Fisher's exact test. Postoperative pain scores were analyzed with Mann Whitney U test. Significance was defined as $p<0.05$. All statistical comparisons were accomplished with SPSS 11.0.

\section{Results}

Fourty-seven children were enrolled in this study. There were no significant differences in age, weight, gender, type of surgery and duration of surgery (Table 2 ).

Intraoperative sevoflurane concentrations were lower in group I patients than group II patients at 10 and 30 minutes $(p<0.05)$ (Table 3 ).

\begin{tabular}{lcc}
\hline & Group I (n=23) & Group II (n=24) \\
\hline Induction & $7.0 \pm 0.0$ & $7.0 \pm 0.0$ \\
5. min. & $1.8 \pm 0.3$ & $1.9 \pm 0.1$ \\
10. min. & $1.5 \pm 0.4^{*}$ & $1.8 \pm 0.2$ \\
15. min. & $1.5 \pm 0.3$ & $1.7 \pm 0.3$ \\
30. min. & $1.4 \pm 0.4^{*}$ & $1.6 \pm 0.2$ \\
45. min. & $1.5 \pm 0.4$ & $1.7 \pm 0.3$ \\
60. min. & $1.4 \pm 0.4$ & $1.6 \pm 0.3$ \\
90. min. & $1.4 \pm 0.4$ & $1.5 \pm 0.4$ \\
120. min. & $1.2 \pm 0.3$ & $1.4 \pm 0.4$ \\
150. min. & $1.1 \pm 0.3$ & $1.3 \pm 0.4$ \\
180. min & $1.1 \pm 0.4$ & $1.4 \pm 0.3$ \\
\hline
\end{tabular}

${ }^{*} \mathbf{p}<0.05$ Group I compared with group II

Table 3. Intraoperative sevoflurane concentration in groups $($ Mean $\pm \mathrm{SD})$ 
There were significant differences between groups in the number of patients requiring rescue analgesia. Seven patients in levobupivacainemorphine group, eighteen patients in levobupivacaine group received rescue analgesia in postoperative 24 hour $(p=0.003)$. Mean time from epidural block to the first analgesic medication (duration of postoperative analgesia) after surgery was $1218.2 \pm 362.2$ minutes in levobupivacaine-morphine group, $671.8 \pm 591.7$ minutes in children receiving only levobupivacaine $(p=0.002)$.

Postoperative CHEOPS were lower in group I patients than in group II patients $(p<0.05)$, (Table 4$)$. Sedation scores evaluated on postoperative minutes at 10,15, 30,45, 60 were higher in group I patients than in group II patients $(p<0.05)$. The patients had no deep sedation. Sedation scores were shown in Table 5 in both groups.

There was no significant change in HR, DBP or SBP during study period in any group. Respiratory depression was not observed, $\mathrm{SpO} 2$ values during and after operation did not differ among the groups. No patient experienced hypotension, bradycardia, or motor block.

\section{Discussion}

In the current study, we compared the relative efficacy of the combination of levobupivacaine and the opioid analgesic morphine versus alone levobupivacaine for postoperative analgesia after major abdominal surgical procedures in children. The primary endpoint of this study was the need for rescue analgesia in the first $24 \mathrm{~h}$ after surgery.

Vas L., and colleagues [13] recently assessed the radiological appearance of contrast injected through epidural catheters in 10 babies aged 2- 36 days (weight 1.8-4.5 kg) after major surgery. The authors found that both the quality and extent of spread were different for every baby. Spread was more extensive after $1 \mathrm{ml} / \mathrm{kg}$ compared with $0.5 \mathrm{ml} / \mathrm{kg}$ (mean $9.3+3.68$ versus $11.5+3.03$ segments;

\begin{tabular}{lcc}
\hline CHEOPS & Group I & Group II \\
\hline Postop. 5. min & $1.0 \pm 0,2^{\star}$ & $1.0 \pm 0.5$ \\
Postop. 10. min. & $1.0 \pm 0.0 \$$ & $1.0 \pm 0.4$ \\
Postop. 15. min. & $1.0 \pm 0.0 \&$ & $1.0 \pm 0.4$ \\
Postop. 30. min. & $1.0 \pm 0.0 €$ & $1.0 \pm 0.4$ \\
Postop. 45. min. & $1.0 \pm 0.0 €$ & $1.0 \pm 0.4$ \\
Postop. 60. min. & $1.0 \pm 0.0$ & $1.0 \pm 0.0$ \\
Postop. 120.min. & $1.0 \pm 0.0$ & $1.0 \pm 0.3$ \\
Postop. 240.min. & $1.0 \pm 0.2$ & $1.0 \pm 0.3$ \\
Postop. 360.min. & $1.0 \pm 0.3$ & $1.0 \pm 0.2$ \\
Postop. 720.min. & $1.0 \pm 0.4$ & $1.0 \pm 0.4$ \\
Postop. 1440min. & $1.0 \pm 0.2$ & $1.0 \pm 0.3$ \\
\hline
\end{tabular}

Table 4. CHEOPS values in groups (Median \pm SD) ${ }^{*} \mathrm{p}=0.006$ Group I compared with group II $\$ \mathrm{p}=0.011$ Group I compared with group II $\& \mathrm{p}=0.022$ Group I compared with group II $€ \mathrm{p}=0.043$ Group I compared with group II
$P=0.014$ ). We used levobupivacaine $0.25 \%$ with bolus epidural injection or $0.125 \%$ levobupivacaine-morphine combination and total volume was limited $0.7 \mathrm{ml} / \mathrm{kg}$. Ivani et al. [14] investigated three different concentration levobupivacaine $(0.125 \%, 0.20 \%$ and $0.25 \%$ in each group) for caudal blockade in a undergoing subumbilical surgery. They found that the use of $0.125 \%$ levobupivacaine for caudal blockade in children was associated shorter duration of postoperative analgesia compared to $0.20 \%$ and $0.25 \%$ concentration. Taylor R., and colleagues [15] assessed the efficacy of $0.25 \%$ levobupivacaine $(0.8$ $\mathrm{ml} / \mathrm{kg}$ ) injected caudally in young children having penile or groin surgery. They reported that adequate intraoperative analgesia in $90 \%$ and a mean time to first postoperative analgesia of $7.3 \mathrm{~h}$. Ivani G., et al. [14] recruited sixty children aged 1-7 years of age having caudal blockade ( $1 \mathrm{ml} / \mathrm{kg}$ of ropivacaine $0.2 \%$, levobupivacaine $0.25 \%$ or bupivacaine $0.25 \%$ ) for either peno-scrotal or groin surgery. They reported that all blocks were successful with a similar time to onset (assessed by pin-prick) in all children and there were no differences in the number of children requiring supplemental analgesia or time to first postoperative dose. We found that adequate postoperative analgesia in all patients and duration of analgesia $671.8 \pm 591.7$ min in group sole levobupivacaine and only 18 patients needed rescue analgesics.

Epidural opioids are commonly used for major surgery in adults and children [16-18]. Epidural morphine may be given as preemptive analgesic agent to achieve rapidly postoperative analgesia [17]. In children, pharmacokinetic parameters of morphine were similar to adults, but a greater total body clearence of morphine [12]. Morphine is rapidly transferred from the epidural space to plasma (max. $10 \mathrm{~min}$.). The caudal or epidural dose of morphine is controversial. In the recent study, Castillo-Zamora C., et al. [10] sugggested that the postoperative analgesia produced by caudal

\begin{tabular}{lcc}
\hline & Group I (n=23) & Group II (n=24) \\
\hline Postop. 5.min. & $1.7 \pm 1.0$ & $1.3 \pm 1.1$ \\
Postop. 10. min & $1.7 \pm 1.1^{*}$ & $1.0 \pm 1.0$ \\
Postop. 15. min & $1.6 \pm 1.0^{*}$ & $0.8 \pm 1.0$ \\
Postop. 30. min & $1.5 \pm 1.0^{*}$ & $0.7 \pm 1.0$ \\
Postop. 45. min & $1.4 \pm 1.0^{*}$ & $0.7 \pm 0.9$ \\
Postop. 60. min & $1.3 \pm 1.0^{*}$ & $0.7 \pm 0.7$ \\
Postop. 120. min & $1.3 \pm 1.0$ & $0.9 \pm 0.9$ \\
Postop. 240. min & $1.1 \pm 0.9$ & $1.0 \pm 0.9$ \\
Postop. 360. min & $1.1 \pm 0.8$ & $1.1 \pm 1.0$ \\
Postop. 720. min & $1.2 \pm 0.9$ & $0.9 \pm 0.9$ \\
Postop. 1440. min & $1.0 \pm 0.7$ & $0.6 \pm 0.7$ \\
\hline
\end{tabular}

Table 5. Sedation scores in groups ( Mean \pm SD) ${ }^{*} \mathrm{p}<\mathbf{0 . 0 5}$ Group I compared with group II 
or by epidural administration of morphine as low as $11 \mu \mathrm{g} / \mathrm{kg}$ was enough to produce satisfactory postoperative analgesia. Senard M., et al. [19] concluded that small dose epidural morphine $(0.1 \mathrm{mg} / \mathrm{h})$ combined with levobupivacaine or ropivacaine produce comparable postoperative analgesia. Attia J., et al. [12] suggested that epidural morphine $(50 \mu \mathrm{g} / \mathrm{kg})$ provided effective and prolonged analgesia in children after abdominal and urological surgery. Bozkurt P., and colleagues [11] evaluated single injection lumbar epidural morphine $(0.1 \mathrm{mg} / \mathrm{kg})$ for postoperative analgesia in children. They reported that duration of the analgesia time $10.9 \pm 5.5$ hours after epidural morphine administration. We used an epidural single dose of the morphine $30 \mu \mathrm{g} / \mathrm{kg}$ with half concentration levobupivacaine $(0.125 \%)$ in our study. We found that duration of analgesia was longer (1218.2 $\pm 362.2 \mathrm{~min}$ ) in levobupivacaine-morphine group than in group only received levobupivacaine $(671.8 \pm 591.7)$. In addition, only 7 patients needed rescue analgesics in this group. This value was significantly different from the sole levobupivacaine group. Prolonged analgesia in group levobupivacaine-morphine may explained as the result of epidural morphine.

Intraoperative sevoflurane concentrations were lower in levobupivacaine-morphine group patients than the levobupivacaine alone group of patients $(p<0.05)$ at 10th and 30th minutes intraoperatively. Özcengiz D., et al. [20] compared the quality and duration of analgesia, the effect on perioperative sevoflurane requirement after a single, presurgical caudal block with either tramadol or morphine in children undergoing inguinal herniorrhaphy. Similarly, they reported that inhaled sevoflurane concentration was significantly lower in group morphine and group tramadol than in the control group.

In previous studies, bupivacaine produced a significant incidence of residual motor block after caudal block compared with levobupivacaine or ropivacaine [14,21]. Also, we did not observe residual motor blockade neither in group levobupivacaine-morphine nor in group levobupivacaine in our study. In addition, no patient experienced any hypotension, bradycardia or respiratory depression.

\section{Conclusion}

Epidural levobupivacaine-morphine combination reduced intraoperative sevoflurane concentration, supplied longer postoperative analgesia and required less rescue postoperative analgesic than sole levobupivacaine, but in contrast, it caused higher sedation level in patient undergoing major abdominal surgery.

\section{Compteting interest}

The authors declare that they have no competing interests.

\section{Article history}

Received: 20-Jan-2012 Revised: 28-Feb-2012

Re-revised: 05-Mar-2012 Accepted: 10-Mar-2012

Published: 12-Mar-2012

\section{References}

1. Uguralp S, Mutus M, Koroglu A, Gurbuz N, Koltuksuz U et al. (2002) Regional anesthesia is a good alternative to general anesthesia in pediatric children surgery: Experience in 1,554. J Pediatr Surg; 37:610-613.

2. Markakis DA: Regional anesthesia in pediatrics. Anesthesiol Clin North America 2000; 18;(2.);355-81.

3. Williams DG, Howard RF: Epidural analgesia in children. A survey of current opinions and practices amongst UK paediatric anaesthetists. Paediatr Anaesth 2003; 13;(9.);769-76.

4. Foster RH, Markham A. (2000) Levobupivacaine . A review of its pharmacology and use as a local anaesthetic. Drugs; 59: 551-579.

5. Gristwood RW: Cardiac and CNS toxicity of levobupivacaine: strengths of evidence for advantage over bupivacaine. Drug Saf 2002; 25; (3.);153-63.

6. McCloskey JJ, Haun SE, Deshpande JK: Bupivacaine toxicity secondary to continuous caudal epidural infusion in children. Anesth Analg 1992; 75;(2.);28790.

7. Frawley GP, Downie S, Huang GH: Levobupivacaine caudal anesthesia in children: a randomized double-blind comparison with bupivacaine. Paediatr Anaesth 2006; 16;(7.);754-60.

8. Dalens B. (2006) Some current controversies in paediatric regional anaesthesia. Curr Opin Anaesthesiol; 19:301-308.

9. Ecoffey C: Pediatric regional anesthesia - update. Curr Opin Anaesthesiol 2007; 20;(3.);232-5.

10. Castillo-Zamora C, Castillo-Peralta LA, Nava-Ocampo AA Dose minimization study of single-dose epidural morphine in patients undergoing hip surgery under regional anesthesia with bupivacaine. Paediatr Anaesth 2005; 15;(1.);29-36.

11. Bozkurt $P$, Kaya G, Yeker $Y$ : Single-injection lumbar epidural morphine for postoperative analgesia in children: a report of 175 cases. Reg Anesth 1997; 22; (3.);212-7.

12. Attia J, Ecoffey C, Sandouk P, Gross JB, Samii K: Epidural morphine in children: pharmacokinetics and CO2 sensitivity. Anesthesiology 1986; $65 ;(6.) ; 590-4$.

13. Vas L, Kulkarni V, Mali M, Bagry H: Spread of radioopaque dye in the epidural space in infants. Paediatr Anaesth 2003; 13;(3.);233-43.

14. Ivani G, De Negri P, Lonnqvist PA, Eksborg S, Mossetti $V_{1}$ Grossetti $\mathrm{R}$, et al.: A comparison of three different concentrations of levobupivacaine for caudal block in children. Anesth Analg 2003; 97;(2.);368-71.

15. Taylor R, Eyres R, Chalkiadis GA, Austin S: Efficacy and safety of caudal injection of levobupivacaine, $0.25 \%$, in children under 2 years of age undergoing inguinal hernia repair, circumcision or orchidopexy. Paediatr Anaesth 2003; 13;(2.);114-21.

16. Crews JC, Hord AH, Denson DD, Schatzman C: A 
comparison of the analgesic efficacy of $0.25 \%$ levobupivacaine combined with $0.005 \%$ morphine, $0.25 \%$ levobupivacaine alone, or $0.005 \%$ morphine alone for the management of postoperative pain in patients undergoing major abdominal surgery. Anesth Analg 1999; 89;(6.);1504-9.

17. Kiffer F, Joly A, Wodey E, Carre P, Ecoffey C: The effect of preoperative epidural morphine on postoperative analgesia in children. Anesth Analg 2001; 93;(3.);598-600.

18. Lerman J, Nolan J, Eyres R, Schily M, Stoddart P et al. (2003) Efficacy, Safety, and Pharmacokinetics of Levobupivacaine with and without Fentanyl after Continuous Epidural Infusion in Children Anesthesiology 99:1166-1174.

19. Senard M, Kaba A, Jacquemin MJ, Maquoi LM, Geortay MP, Honore PD, et al.: Epidural levobupivacaine $0.1 \%$ or ropivacaine $0.1 \%$ combined with morphine provides comparable analgesia after abdominal surgery. Anesth Analg 2004; 98;(2.);38994.

20. Ozcengiz D, Gunduz M, Ozbek H, Isik G: Comparison of caudal morphine and tramadol for postoperative pain control in children undergoing inguinal herniorrhaphy. Paediatr Anaesth 2001; 11;(4.);45964.

21. Ivani $G$, DeNegri $P$, Conio $A$, Grossetti $R$, Vitale $P$, Vercellino $C$, et al.: Comparison of racemic bupivacaine, ropivacaine, and levo-bupivacaine for pediatric caudal anesthesia: effects on postoperative analgesia and motor block. Reg Anesth Pain Med 2002; 27;(2.);157-61.

\section{Citation:}

önal D, hatipoglu z, Ozcengiz D, Gunes Y and Gündüz M: Epidural levobupivacaine versus levobupivacainemorphine in postoperative analgesia for paediatric patients. journal of Anesthesiology and Clinical Science 2012, 1:3.

http://www.hoajonline.com/jacs/2049-9752/1/3 